\section{Can We Expect Patients to Question Health Care Workers' Hand Hygiene Compliance?}

To the Editor-Hand hygiene $(\mathrm{HH})$ is one of the most effective means of tackling healthcare-associated infections. ${ }^{1}$ However, rates of compliance remain less than optimal. ${ }^{2}$ Empowering patients to speak with their health care worker (HCW) about $\mathrm{HH}$ is another potential means of improving $\mathrm{HH}$ compliance and has specifically been included in World Health Organization guidelines. ${ }^{3}$

Factors affecting patient engagement in an empowerment program are not well studied. Our hypothesis was that certain characteristics, such as HCW seniority, sex, and profession, make patients more or less inclined to question them.

The aim of this pilot program was twofold: first, to determine whether the simple intervention of giving patients a brochure that gave them permission to ask HCWs to clean their hands was an effective means of patient empowerment, and second, to explore which characteristics of HCWs affect patients' willingness to ask them to clean their hands.

We conducted a 4-week prospective pilot program involving the distribution of a brochure that invited patients to ask their HCW whether they had cleaned their hands. A followup interview was conducted, and the key measure was whether, after reading the brochure, patients would be willing to ask HCWs to clean their hands. In addition, patients were shown photographs of 4 doctors of differing sex and seniority and were asked which of these doctors they would ask to clean their hands. A senior doctor was defined as a doctor with over 20 years of clinical experience. Patients were asked identical questions about nurses of different sex and seniority.

The program was conducted in 7 wards (medical and surgical) in an Australian tertiary care hospital with a strong $\mathrm{HH}$ program. All new patients admitted to the selected wards received the brochure but did not receive a follow-up interview if they were unable to read or understand it.

Analysis was conducted using Stata software, version 11 (Stata). Comparisons were made using Student $t$ test and $\chi^{2}$ test where appropriate, with statistical significance set at $P<.05$. Risk ratios (RRs) with $95 \%$ confidence intervals (CIs) were also calculated for patient responses. Binary variable using the mean age (56 years) was used for age-related calculations.

Forty-six patients were included in the final study ( 27 male and 19 female patients). The mean age was 56 years (range, 21-83 years). After reading the brochure, all patients believed that they should have a role in their own safety and that $\mathrm{HH}$ played a part in this. Forty-three $(93.5 \%)$ believed that they should be involved in improving $\mathrm{HH}$ in the hospital.

Figure 1 displays the percentage of patients who would ask each type of HCW to clean their hands. Patients were sig-

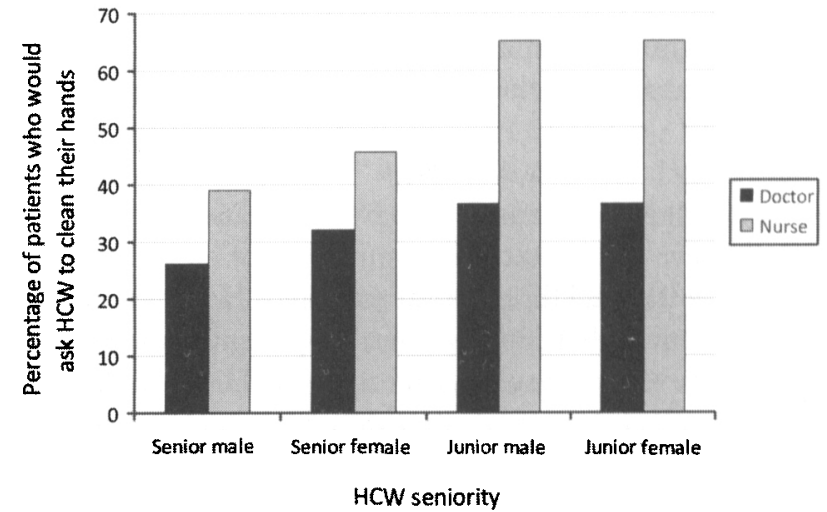

FIGURE 1. Percentage of patients who would ask each type of health care worker (HCW) to clean their hands.

nificantly less willing to ask a doctor to clean their hands than to ask a nurse (RR, $0.61 ; 95 \% \mathrm{CI}, 0.41-0.93 ; P=.02$ ). Patients claimed that they would ask their doctor to clean their hands $43 \%$ of the time, although there was no difference in willingness to ask based on seniority or sex. Patients claimed that they would ask nurses to clean their hands $67 \%$ of the time, and although there was no difference in willingness to ask based on sex, patients were more willing to ask a junior nurse than to ask a senior nurse (RR, $0.65 ; 95 \%$ $\mathrm{CI}, 0.43-0.97 ; P=.04)$. Patients younger than 56 years were 3.5 times more likely ( $95 \% \mathrm{CI}, 1.03-11.92 ; P=.04$ ) to ask a doctor to clean their hands and 4.5 times more likely to ask a male HCW to clean their hands (95\% CI, 1.07-17.30; $P=.03$ ), compared with patients older than 56 years.

The results from our program demonstrate that, even with education, patient are willing to confront their HCW less than half the time and are particularly reluctant to confront their doctors. The reluctance of patients to ask physicians, compared with nurses, has been demonstrated in previous studies, ${ }^{4-6}$ with $20 \%$ of patients in one inpatient survey stating they did not want doctors to think they were questioning their professional ability. ${ }^{6}$ Younger patients were significantly more likely to ask a HCW to clean their hands, compared with older patients, which may reflect generational attitudes and practices. In particular, patient age may affect attitudes towards the $\mathrm{HCW}$-patient interaction.

Our program demonstrated a substantial difference between patient intent and patient action. Although all patients acknowledged that $\mathrm{HH}$ plays a part in their own safety and most wanted a role in preserving it, this did not translate into a willingness to question HCWs. Our findings are similar to those of a study that found that, although $71 \%$ of patients believed that they should be involved in helping improve $\mathrm{HH}$, only $38 \%$ would do anything if they noticed that a HCW had not cleaned their hands. 
The main limitation of our study was the small sample size. Patients were excluded from the program because of language, poor literacy, poor eyesight, and cognitive impairment, which are important considerations for the design of future programs. Limitations aside, this study represents a real-time snapshot of the wards of a busy urban tertiary care hospital.

The French proverb that states "a doctor is often more to be feared than the disease" is relevant, because doctors consistently have the lowest $\mathrm{HH}$ compliance of all $\mathrm{HCWs},{ }^{8}$ and this represents a real threat to patient safety. However, patients fear questioning their doctors. Similar patient empowerment programs have shown success in increasing $\mathrm{HH}$ compliance, ${ }^{5,9}$ which suggests that patient empowerment could be harnessed on an increased scale to improve compliance of HCWs. ${ }^{10}$ Our program has demonstrated that future research should specifically address the patient-doctor relationship and ways to facilitate open communication. Future programs must specifically target age and culturally appropriate interventions that translate patient intent into action.

\section{ACKNOWLEDGMENTS}

Potential conflicts of interest. All authors report no conflicts of interest relevant to this article. All authors submitted the ICMJE Form for Disclosure of Potential Conflicts of Interest, and the conflicts that the editors consider relevant to this article are disclosed here.

\section{Natalie Reid, MBBS; ${ }^{1}$ Jason Moghaddas, MBBS; Michael Loftus, MBBS; ${ }^{1}$ Rhonda L. Stuart, MBBS, FRACP, PhD; ;,2 Despina Kotsanas, BSc(Hons), MClinEpi; ${ }^{2}$ Carmel Scott, $\mathrm{RN}^{3}$ Claire Dendle, MBBS, FRACP, GCHPE ${ }^{1,2}$}

Affiliations: 1. Southern Clinical School, Faculty of Medicine, Monash University, Clayton, Victoria, Australia; 2. Infectious Diseases Department, Southern Health, Clayton, Victoria, Australia; 3. Department of Infection Control, Southern Health, Clayton, Victoria, Australia.

Address correspondence to Claire Dendle, Infectious Diseases Department, Southern Health, Department of Medicine, Monash University, 246 Clayton Road, Clayton, Victoria, Australia 3168 (claire.dendle@monash.edu). Infect Control Hosp Epidemiol 2012;33(5):531-532

(C) 2012 by The Society for Healthcare Epidemiology of America. All rights reserved. 0899-823X/2012/3305-0017\$15.00. DOI: $10.1086 / 665309$

\section{REFERENCES}

1. Boyce JM, Pittet D. Guideline for hand hygiene in health-care settings: recommendations of the Healthcare Infection Control Practices Advisory Committee and the HICPAC/SHEA/APIC/ IDSA Hand Hygiene Task Force. Infect Control Hosp Epidemiol 2002;23 (suppl):S3-S40.

2. Pittet D. Improving compliance with hand hygiene in hospitals. Infect Control Hosp Epidemiol 2000;21:381-386.

3. World Health Organization (WHO). WHO Guidelines on Hand Hygiene in Health Care: World Health Organization 2009. http: //www.who.int/gpsc/country_work/en/ Accessed January 3, 2012.

4. McGuckin $M$, Waterman $R$, Porten $L$, et al. Patient education model for increasing handwashing compliance. Am J Infect Control 1999;27:309-314.

5. McGuckin M, Waterman R, Storr IJ, et al. Evaluation of a patient-empowering hand hygiene programme in the UK. $J$ Hosp Infect 2001;48:222-227.

6. Pittet D, Panesar SS, Wilson $\mathrm{K}$, et al. Involving the patient to ask about hospital hand hygiene: a National Patient Safety Agency feasibility study. J Hosp Infect 2011;77:299-303.

7. National Patient Safety Agency. Achieving Our Aims: Evaluating the Results of the Pilot CleanyourHands Campaign. London: NPSA, 2004. http://www.npsa.nhs.uk/search/?q = cleanyourhands + campaign. Accessed January 3, 2012.

8. Grayson ML, Russo PL, Cruickshank M, et al. Outcomes from the first 2 years of the Australian National Hand Hygiene Initiative. Med J Aust 2011;195:615-619.

9. Longtin Y, Sax H, Allegranzi B, Hugonnet S, Pittet D. Patients' beliefs and perceptions of their participation to increase healthcare worker compliance with hand hygiene. Infect Control Hosp Epidemiol 2009;30:830-839.

10. McGuckin M, Storr J, Longtin Y, Allegranzi B, Pittet D. Patient empowerment and multimodal hand hygiene promotion: a winwin strategy. Am J Med Qual 2011;26:10-17.

\section{Impact of the Change in Surveillance Definitions on the Rates of Urinary Tract Infection in Intensive Care Units: 1988 versus 2009 Definitions}

To the Editor-Urinary tract infection (UTI) is the most common type of healthcare-associated infection, accounting for more than $20 \%-30 \%$ of infections in acute care hospitals. ${ }^{1,2}$ Since 1988, the US Centers for Disease Control and Prevention (CDC) has categorized healthcare-associated UTI as symptomatic UTI (SUTI) or asymptomatic bacteriuria (ASB). This categorization was not changed in the 2004 National Nosocomial Infections Surveillance definitions and the 2008 National Healthcare Safety Network (NHSN) definitions. ${ }^{3,4}$ These surveillance definitions for UTI were revised by the CDC/NHSN in 2009. There were 2 major changes: (1) the category ASB UTI was removed and substituted with the category asymptomatic bacteremic UTI (ABUTI) and (2) the length of time that an indwelling catheter had to be present prior to the onset of catheter-associated UTI (CAUTI) was shortened from 7 to 2 days. To our knowledge, however, the impact of these changes has not been prospectively evaluated. Therefore, using the 1988 and 2009 definitions of UTI we prospectively assessed and compared the rates of UTIs among patients admitted to a medical intensive care unit (MICU) and a surgical intensive care unit (SICU).

This study was performed in Seoul, Republic of Korea, at 